\title{
Stresses as First-Line Tools for Enhancing Lipid and Carotenoid Production in Microalgae
}

\author{
Tian-Qiong Shit, Ling-Ru Wang ${ }^{\dagger}$, Zi-Xu Zhang, Xiao-Man Sun* and He Huang \\ School of Food Science and Pharmaceutical Engineering, Nanjing Normal University, Nanjing, China
}

\section{OPEN ACCESS}

Edited by:

Eduardo Jacob-Lopes, Federal University of Santa Maria,

Brazil

Reviewed by:

José Carlos Pires,

University of Porto, Portugal

I-Son Ng,

National Cheng Kung University,

Taiwan

*Correspondence:

Xiao-Man Sun

xiaomansun@njnu.edu.cn

${ }^{\dagger}$ These authors have contributed equally to this work

Specialty section:

This article was submitted to

Bioprocess Engineering,

a section of the journal

Frontiers in Bioengineering and

Biotechnology

Received: 23 February 2020 Accepted: 18 May 2020

Published: 23 July 2020

Citation:

Shi T-Q, Wang L-R, Zhang Z-X,

Sun X-M and Huang $H$ (2020)

Stresses as First-Line Tools

for Enhancing Lipid and Carotenoid

Production in Microalgae.

Front. Bioeng. Biotechnol. 8:610.

doi: 10.3389/fbioe.2020.00610
Microalgae can produce high-value-added products such as lipids and carotenoids using light or sugars, and their biosynthesis mechanism can be triggered by various stress conditions. Under nutrient deprivation or environmental stresses, microalgal cells accumulate lipids as an energy-rich carbon storage battery and generate additional amounts of carotenoids to alleviate the oxidative damage induced by stress conditions. Though stressful conditions are unfavorable for biomass accumulation and can induce oxidative damage, stress-based strategies are widely used in this field due to their effectiveness and economy. For the overproduction of different target products, it is required and meaningful to deeply understand the effects and mechanisms of various stress conditions so as to provide guidance on choosing the appropriate stress conditions. Moreover, the underlying molecular mechanisms under stress conditions can be clarified by omics technologies, which exhibit enormous potential in guiding rational genetic engineering for improving lipid and carotenoid biosynthesis.

Keywords: microalgae, stresses, lipids, carotenoids, omics technologies

\section{INTRODUCTION}

Microalgae have been considered as an alternative source of lipids and carotenoids (Chisti, 2007), the accumulations of which can usually be induced by stress conditions (Pribyl et al., 2012). Under extreme environmental conditions, microalgae synthesize and produce various secondary metabolites to retain their growth rate. In general, lipids act as an energy-rich carbon storage battery that enables the cells to survive under transient harsh environmental conditions (Hellier et al., 2015). A number of studies showed that stress conditions increased levels of intracellular reactive oxygen species (ROS), which in turn changed the carbon metabolic flux from glycolysis to the oxidative pentose phosphate pathway and subsequently resulted in the excessive accumulation of intracellular equivalents of excessive reduction, such as NADPH (Hu et al., 2008; Shi et al., 2017). In order to protect microalgae cells from the excessive reduction equivalents produced under stress, lipid, rather than protein or carbohydrate, was accumulated in large quantities due to the greater demands of NADPH. However, high levels of ROS can also cause damage to biological 


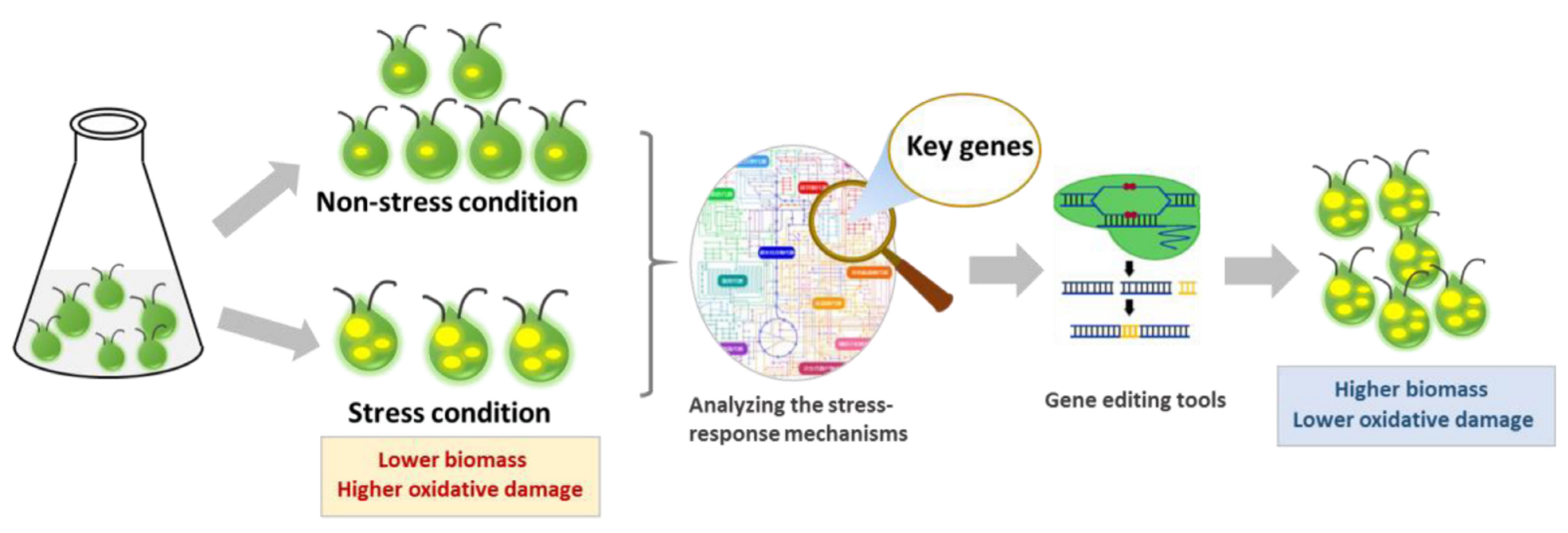

GRAPHICAL ABSTRACT | Development of new production microalgae strains with high lipid production capacity and cell growth with the aids of gene editing tools for selecting key genes under stress conditions.

macromolecules such as DNA, lipids, and proteins (Ruenwai et al., 2011). To counter this danger, microalgae synthesize additional amounts of carotenoids to scavenge ROS under stress conditions.

Carotenoids can form a protective layer to prevent reactive radicals and lipid peroxidation. Moreover, carotenoids are important for maintaining the functionality of the photosynthetic apparatus and the integrity of membranes, which is essential for cell survival. Carotenoids can be divided into primary and secondary classes. Primary carotenoids are growth coupled metabolites located in the mitochondria membranes and chloroplast that suffer degradation under stress. Among the primary carotenoids, lutein is particularly prominent since it acts to maintain the membrane integrity and protects cells under many stress conditions (Sanchez et al., 2008). By contrast, secondary carotenoids can be produced under stress conditions. Astaxanthin is considered a typical secondary carotenoid and is present in cytoplasmic lipid bodies outside the chloroplasts (Lemoine and Schoefs, 2010). Moreover, primary carotenoids such as lutein are degraded under stress, while secondary carotenoids remain largely unaffected (Del Campo et al., 2000). However, several primary carotenoids, such as $\beta$-carotene, also accumulate under stress conditions and act as secondary metabolites (Hermawan et al., 2018).

Many of strategies have been developed for overcoming the limitations of growth inhibition and oxidative damage, including two-stage cultivation strategies and the addition of growthpromoting agents (Figure 1). In fact, there are many inseparable links between the production of lipids and of carotenoids. Firstly, their biosynthesis pathways share the same precursor substrate, acetyl-CoA. Secondly, scavenging ROS from lipid peroxidation is an important characteristic of carotenoids. Lastly, carotenoids are toxic to the cell, so lipid droplets can act as "storerooms" for carotenoids (Ma et al., 2018). In this review, we summarize recent studies on stress-based fermentation strategies for the induction of lipid and carotenoid production in microalgae, including nutrient-related stresses and environmental stresses (Table 1). The underlying molecular mechanisms of the behavior of specific strains under stress conditions can increasingly also be clarified using omics technologies, which can guide rational genetic engineering for improving the biosynthesis of lipids and carotenoids.

\section{THE EFFECTS OF NUTRIENT-RELATED STRESSES AND GENERALIZED STRESS-RESPONSE MECHANISMS}

\section{Nitrogen Limitation \\ Performance}

A linear relationship between the concentration of the nitrogen source and lipid content was observed in many microalgal species (Hsieh and Wu, 2009). For example, lipid production increased 93\% in Chlamydomonas reinhardtii, and Acutodesmus dimorphus accumulated $75 \%$ neutral lipids among total lipids under nitrogen-deficient conditions (Chokshi et al., 2017; Yang et al., 2018). It is possible that nitrogen-deficient conditions might improve microalgal lipid biosynthesis by affecting other biochemical pathways (Srinuanpan et al., 2018). The production of carotenoids, including $\beta$-carotene, astaxanthin, and lutein, was also successfully enhanced by nitrogen limitation in Chlorella zofingiensis, Dunaliella salina, Neochloris oleoabundans, and Muriellopsis sp. (Del Campo et al., 2000; Mulders et al., 2014; Urreta et al., 2014). Nitrogen deprivation can also promote the concomitant accumulation of both lipids and the antioxidant pigment astaxanthin in microalgae (Chen et al., 2015; Liu J. et al., 2016).

\section{Possible Mechanisms}

On the one hand, low nitrogen levels reduce competition for carbon, which is required for the synthesis of both carotenoids and proteins, since only the latter require nitrogen (Wang et al., 2019). Another possible reason might be the degradation of nitrogenous compounds such as chlorophyll and proteins, which might provide carbon or energy for the accumulation of lipids (Liu T. et al., 2016). Moreover, it has been reported that nitrogen deficiency can upregulate diacylglycerol acyltransferase (DGAT), which catalyzes the last step of TAG assembly in 


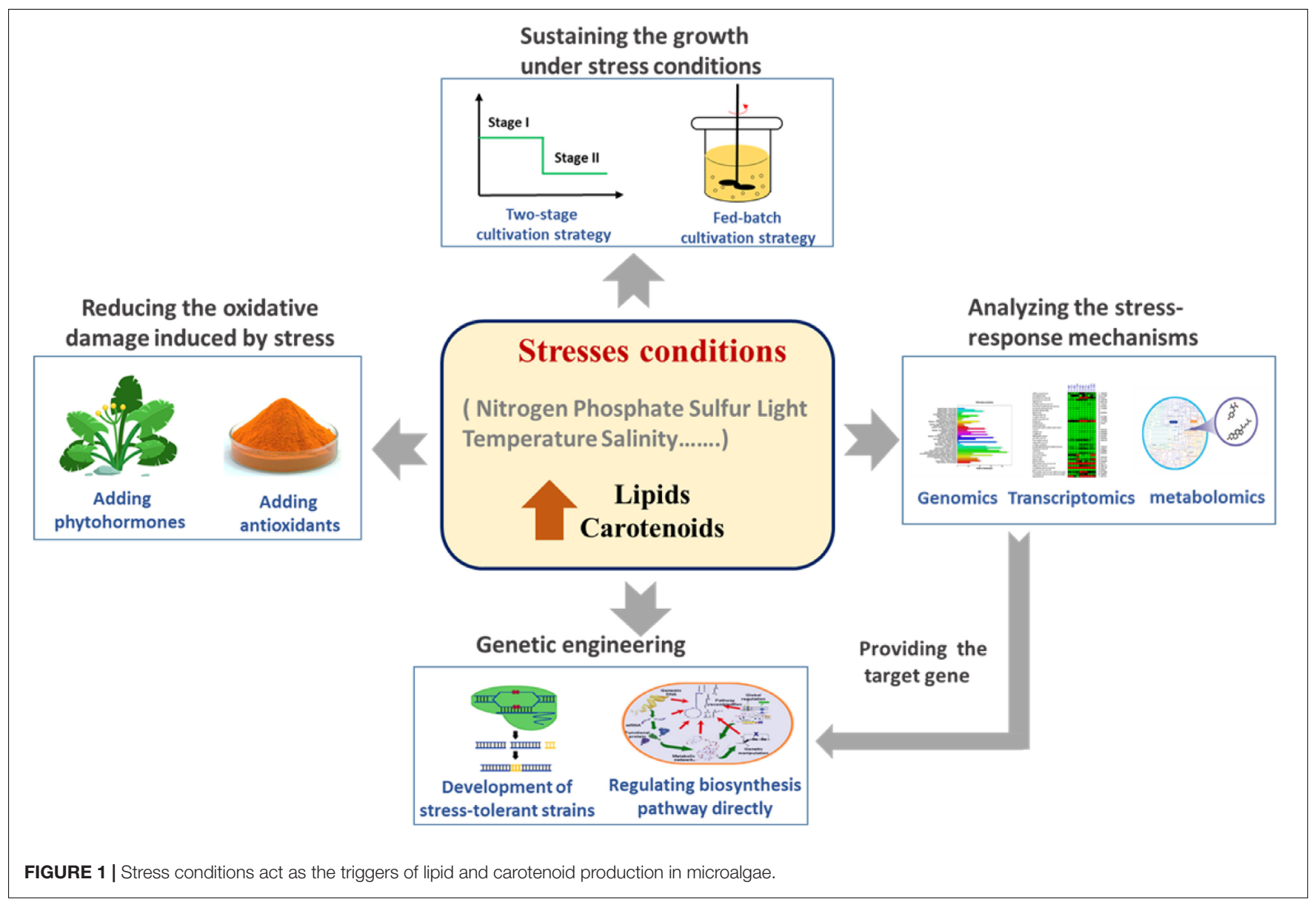

many microalgal species (Li-Beisson et al., 2015). Overall, these adaptive responses help to ensure the survival of cells during times of stress. While lipids serve as energy stores, astaxanthin seems to play a role in the protection against ROS (Rosenberg et al., 2008).

\section{Phosphate Limitation \\ Performance}

Phosphate limitation also has a positive effect on the accumulation of lipids or carotenoids (Li X. et al., 2010; Shen et al., 2020). Sun et al. (2014) found that phosphate limitation shortened the fermentation time, leading to the highest DHA productivity of $291 \mathrm{mg} \mathrm{L}^{-1} \mathrm{~h}^{-1}$ in Schizochytrium sp. Interestingly, Chu et al. (2014) found that a combination of sufficient phosphorus and nitrogen starvation was the real "lipid trigger." It has been reported that expressions of enzymes involved in glycolysis and pentose phosphate pathway were enhanced greatly under nitrogen limitation (Rai et al., 2017), which indicated that more energy was needed in this process. Inorganic phosphate is important to cellular energy transduction (Beardall et al., 2005). Based on this, sufficient phosphorus can improve biomass productivity in the nitrogen starvation stage, which has been shown in Chlorella sp. and Scenedesmus obliquus (Fu et al., 2017; Shen et al., 2020). Therefore, regulating lipid production through a combination of sufficient phosphorus and nitrogen starvation seems to be an economical and environmentally friendly approach.

\section{Possible Mechanisms}

Phosphate can influence carbon flow between the starch and lipid synthesis pathways by regulating the activity of ADP-glucose pyrophosphorylase (Yao et al., 2018), which is the first committed step of starch synthesis. Since starch biosynthesis shares common carbon precursors with lipid biosynthesis, blocking the starch biosynthesis pathway can increase the metabolic flux toward lipid accumulation. Inhibition of ADP-glucose pyrophosphorylase in Chlamydomonas resulted in a 10-fold increase of lipid yield (Li Y. et al., 2010).

\section{Sulfur Limitation \\ Performance}

Sulfur limitation is also beneficial for lipid production in microalgae. For example, sulfur starvation was found to be more effective for increasing TAG production in C. reinhardtii than was nitrogen and phosphorus depletion (Sakarika and Kornaros, 2017). It has been reported that starvation of sulfur is more efficient than that of phosphorus or iron for inducing highlevel accumulation of astaxanthin (Boussiba and Vonshak, 1991). However, phosphorus starvation led to the highest increase of $\beta$ carotene accumulation in another report (Phadwal and Singh, 
TABLE 1 | Effect of various stresses on the lipid and carotenoid production of microalgae.

\begin{tabular}{|c|c|c|c|}
\hline Microalgae & Stress condition & Performance & References \\
\hline C. vulgaris & Nitrogen limitation & Lipid content (\% biomass) was increased from 30 to $89 \%$ & Shen et al. (2020) \\
\hline N. oleoabundans & Nitrogen limitation & Lipid yield was increased 2-fold & Li et al. (2008) \\
\hline C. vulgaris & Nitrogen limitation & Lipid productivity was increased from 226.5 to $305.7 \mathrm{mg} \mathrm{L}^{-1}$ day $^{-1}$ & Liu T. et al. (2016) \\
\hline C. zofingiensis & Nitrogen limitation & Carotenoid content was increased from 0.05 to $4.5 \mathrm{mg} \mathrm{g}^{-1}$ & Mulders et al. (2014) \\
\hline D. salina & Nitrogen limitation & $\begin{array}{l}\beta \text {-carotene productivity was increased from } 1.28 \text { to a maximum of } \\
14.4 \mathrm{~g} \mathrm{LCV}^{-1} \text { day }^{-1}\end{array}$ & Lamers et al. (2012) \\
\hline Scenedesmus sp. & Phosphorus limitation & Lipid content was increased from 30\% to 53\% & LiX. et al. (2010) \\
\hline B. braunii & Phosphorus limitation & Lipid yield was increased from 218 to $416 \mathrm{~g} \mathrm{~L}^{-1}$ & Shen et al. (2020) \\
\hline C. regularis & $\begin{array}{l}\text { Sufficient phosphorus } \\
\text { and mitrogen limitation }\end{array}$ & $\begin{array}{l}\text { Lipid content was increased from } 24.3 \% \text { ( } 50 \mathrm{mg} \mathrm{L}{ }^{-1} \text { nitrogen }+45 \mathrm{mg} \mathrm{L}-1 \\
\text { phosphorus) to } 42.3 \% \text { ( } 250 \mathrm{mg} \mathrm{L}^{-1} \text { nitrogen }+5.5 \mathrm{mg} \mathrm{L}^{-1} \text { phosphorus) }\end{array}$ & Fu et al. (2017) \\
\hline C. vulagris & Sulfur limitation & The maximum total lipid content of $53.43 \pm 3.93 \% \mathrm{~g} \mathrm{gDW}^{-1}$ was obtained & Sakarika and Kornaros (2017) \\
\hline P. tricornutum & High light & TAG productivity was increased from 15.58 to $31.39 \mathrm{mg} \mathrm{L}^{-1}$ day $^{-1}$ & He et al. (2015) \\
\hline C. protothecoides & High light & $\begin{array}{l}\text { Total lipid content increased from } 24.8 \text { to } 37.5 \% \text {, and C16-18 fatty acids } \\
\text { increased from } 76.97 \text { to } 90.24 \%\end{array}$ & Kurpan Nogueira et al. (2015) \\
\hline Desmodesmus sp. & High light & A maximum lutein productivity of $3.6 \mathrm{mg} \mathrm{L}^{-1}$ day $^{-1}$ was obtained & Lamers et al. (2010) \\
\hline D. salina & High light & The highest $\beta$-carotene production of $30 \mathrm{pg} \mathrm{cell}^{-1}$ day $^{-1}$ was obtained & Xie et al. (2013) \\
\hline H.pluvialis & $\begin{array}{l}\text { Nitrogen limitation and } \\
\text { high light }\end{array}$ & Lipid and astaxanthin production reached 40.69 and $1.85 \%$, respectively & Zhao et al. (2018) \\
\hline A. mangrovei & Lower temperature & The DHA fraction was increased from 29 to $42 \%$ & Kanokwan and Cornelis (2012) \\
\hline N.salina & Lower temperature & EPA content was increased 2- to 3-fold. & Guedes et al. (2010) \\
\hline Muriellopsis sp. & High temperatures & A maximum lutein content of $0.54 \%$ d.wt. at $44^{\circ} \mathrm{C}$ was acquired & Del Campo et al. (2000) \\
\hline C. protothecoides & High salinity & $\begin{array}{l}\text { The highest lipid content of } 41.2 \% \text { and lipid yield of } 185.8 \mathrm{mg} \mathrm{g}^{-1} \text { were } \\
\text { obtained under } 30 \mathrm{~g} \mathrm{~L}^{-1} \mathrm{NaCl} \text { condition }\end{array}$ & Wang et al. (2016) \\
\hline C. vulgaris & High salinity & $\begin{array}{l}\text { The lipid content was enhanced from } 60 \text { to } 70 \% \text { when the } \mathrm{NaCl} \\
\text { concentration was increased from } 0.5 \text { to } 1.0 \mathrm{M}\end{array}$ & Takagi et al. (2006) \\
\hline H. pluvialis & High salinity & The maximum astaxanthin content of $5.01 \mathrm{mg} \mathrm{g}^{-1}$ was obtained & Ding et al. (2019) \\
\hline D. salina & High salinity & Resulted in a 30-fold increase in $\beta$-carotene production & Coesel et al. (2008) \\
\hline
\end{tabular}

2003). Therefore, the effect of sulfur limitation on lipids and carotenoids depends on the microalgae species.

\section{Possible Mechanisms}

Sulfur is necessary for the synthesis of the key antioxidant molecule glutathione (GSH; Carfagna et al., 2016), which participates in the stress response by scavenging ROS. Therefore, an increase of ROS caused by sulfur limitation and a consequent decrease of intracellular GSH concentration can enhance the production of carotenoids as alternative ROS scavengers. Additionally, many authors suggested that GSH might act as a "sensor" of the cell's sulfur status, thus regulating the rate of sulfur assimilation (Carmen Ruiz-Dominguez et al., 2015; Carfagna et al., 2016).

\section{THE EFFECTS AND GENERALIZED MECHANISMS OF ENVIRONMENTAL STRESSES}

\section{Light Stress}

\section{Performance}

Under high light intensity, the total polar lipid content decreased, while the contents of neutral storage lipids increased ( $\mathrm{Hu}$ et al., 2008). Based on these findings, high light intensity was used to trigger the accumulation of neutral lipids in Phaeodactylum tricornutum, Chlorella sp., and Chlorella protothecoides (He et al., 2015; Krzeminska et al., 2015; Kurpan Nogueira et al., 2015). Light stress has often been applied in conjunction with nitrogen (Ho et al., 2015; Remmers et al., 2017), salinity (Pal et al., 2011), and temperature stress (Kurpan Nogueira et al., 2015). Zhao et al. (2018) showed that a combination of nitrogen limitation and high light stress simultaneously increased the accumulation of lipids and astaxanthin in Haematococcus pluvialis, which reached 40.69 and $1.85 \%$ of the cell dry weight, respectively. Under high light intensity, maximum lutein productivity $\left(3.6 \mathrm{mg} \mathrm{L}^{-1}\right.$ day $\left.^{-1}\right)$ and $\beta$-carotene productivity (30 pg cell ${ }^{-1} \mathrm{day}^{-1}$ ) were obtained in Desmodesmus sp. and D. salina, respectively (Lamers et al., 2010; Xie et al., 2013).

\section{Possible Mechanisms}

Directly, high light intensity promotes the cell growth of microalgae by enhancing photosynthesis. Some studies indicated that increased light intensity resulted in an increase in superoxide and hydrogen peroxide, which induced oxidative damage to polyunsaturated fatty acids (PUFAs), which finally resulted in a higher neutral lipid content and lower polar lipid content (He et al., 2015). Conversely, low light conditions are often reported as a factor for increasing the PUFA contents, which might be due to an increase of the amount of thylakoid membranes to counterbalance the lower availability of light (Remmers et al., 2017). High light intensity can boost the 
expression levels of the lycopene beta-cyclase gene (Ramos et al., 2008), which is the key enzyme for carotenoid accumulation in microalgae. Moreover, Coesel et al. (2008) also suggested that high light stress can regulate the activity of phytoene synthase and phytoene desaturase.

\section{Temperature Stress Performance}

It has been shown that many microalgae display increased growth and total lipid production at higher temperatures (Sayegh and Montagnes, 2011). Examples include Nannochloropsis salina and Ettlia oleoabundans (Converti et al., 2009; Yang et al., 2013). In fact, temperature stress has a greater effect on the lipid composition than on total lipid yield, especially for PUFA biosynthesis (Guedes et al., 2010; Van Wagenen et al., 2012). However, high temperatures are beneficial for lutein accumulation in microalgae such as Muriellopsis sp. and Scenedesmus almeriensis (Del Campo et al., 2000; Sanchez et al., 2008). By contrast, slightly low temperature during the night period was beneficial for both growth and astaxanthin accumulation in $H$. pluvialis (Wan et al., 2014). Thus, the optimum culture conditions are different in different microalgae species because of the localized sensitivity of microalgae to nutrients, and the optimal nutrient concentrations for one strain may inhibit the growth of other strains.

\section{Possible Mechanisms}

At lower temperature, more PUFAs are synthesized and incorporated into the membrane to maintain its fluidity. Moreover, Ward and Singh (2005), as well as An et al. (2013), view the higher proportion of unsaturated fatty acids at lower temperatures as mainly a consequence of the higher dissolved oxygen concentration under these conditions, which directly stimulates the function of oxygen-dependent desaturases. It has been reported that higher temperatures result in increased photooxidative stress, which is correlated with increased carotenoid production in microalgal species (Tripathi et al., 2002). Low temperature decreases the nutrient uptake rate and slows lutein accumulation (Bhosale, 2004).

\section{Salinity Stress Performance}

The stimulating effect of increased salinity on lipid accumulation can be attributed to osmotic stress in terms of cellular responses (Pugkaew et al., 2019). Lipid accumulation in Chlorella vulgaris and Dunaliella sp. was greatly increased under high salinity stress, reaching 21.1 and 70\%, respectively (Takagi et al., 2006). Interestingly, salt stress can also have a positive effect on the production of astaxanthin and $\beta$-carotene. For instance, the maximum astaxanthin content of $5.01 \mathrm{mg} \mathrm{g}^{-1}$ was obtained in H. pluvialis when treated with $0.2 \mathrm{~g} \mathrm{~L}^{-1} \mathrm{NaCl}$, which was $42 \%$ higher than that of the control (Ding et al., 2019). A general enhancement of astaxanthin production was also observed in C. zofingiensis at $\mathrm{NaCl}$ concentrations of up to $0.2 \mathrm{M}$ (Campo et al., 2004). A moderate increase in salt concentration from 4 to $9 \%$ resulted in a 30 -fold increase of $\beta$-carotene accumulation in D. salina (Coesel et al., 2008). However, salinity stress did not affect the content of lutein (Sanchez et al., 2008).

\section{Possible Mechanisms}

Salinity stress was regarded as a powerful regulator for switching the carbon distribution from starch to lipids in microalgae (Ho et al., 2017). Under high salinity stress, lipid production was increased, while the protein and starch content decreased. It was founded that ACCase (the key enzyme of lipid synthesis) was upregulated and AGPase (the key enzyme of starch synthesis) was downregulated. Moreover, the mRNA levels of key enzymes involved in starch degradation were greatly upregulated (Ho et al., 2017), which further proved that salinity induced the conversion of starch to lipids. In addition, salinity stress induced ROS generation. It has been proved that ROS can trigger lipid overproduction via several pathways. For example, ROS can enhance the activity of ACCase enzyme and regulate cellular autophagy (Goodson et al., 2011).

\section{APPLICATION OF "OMICS" TECHNOLOGIES}

The stress-response mechanisms of different microalgal species sometimes differ greatly. Although these systems are complex and involve a great number of genes, "omics" approaches, such as genomics, transcriptomics, proteomics, metabolomics, and lipidomics, offer powerful tools for examining the differential expression or regulation of genes under stress conditions (Guarnieri and Pienkos, 2015). It will be important to understand the key factors responsible for the overproduction of lipids, since this knowledge can be used to identify target genes for genetic engineering.

\section{Unraveling the Stress-Response Mechanisms of Microalgae}

As the most commonly utilized method for lipid production, it is critical to investigate relevant metabolic regulation mechanisms under nitrogen limitation. For example, in P. tricornutum, a label-free quantitative proteomics approach revealed that nitrogen starvation significantly upregulated the expression of the $\beta$-subunit of methylcrotonyl-CoA carboxylase (MCC2) and that inhibition of MCC2 expression resulted in decreased lipid accumulation (Ge et al., 2014). Metabolomic analysis revealed that the PSR1 gene (phosphorus starvation response) is critical for lipid accumulation in response to phosphorus starvation (Bajhaiya et al., 2016). Recently, a lipidomic analysis of Thalassiosira pseudonana under phosphorus limitation found that the abundance of several diglycosylceramide lipids was increased up to 10 -fold, revealing a novel class of substitute lipids and potential biomarkers for the study of phosphorus limitation (Hunter et al., 2018).

To obtain insights into the astaxanthin synthesis mechanism under high light conditions, Gwak et al. (2014) used transcriptome analysis and found that beta-carotene hydroxylase (BKT or crtZ), phytoene synthase (PSY), and phytoene desaturase (PDS) were all upregulated in $\mathrm{H}$. pluvialis under high irradiance. 
Analogously, transcriptome analysis of $H$. pluvialis revealed that high light intensities impacted the expression of genes involved in the carotenoid biosynthesis pathway, including PDS, crtISO, LcyB, LUT1, LUT5, and ZEP (Gwak et al., 2014; He et al., 2018). When the crtO ketolase gene was overexpressed in $H$. pluvialis, the accumulation of astaxanthin and other ketocarotenoids was greatly increased (Kim and Portis, 2004).

Under cold stress, the cellular content of PUFAs can be significantly increased to maintain membrane fluidity and functions. Consequently, Ma et al. (2015) used Illumina's sequencing technology to examine global changes in the transcriptome of Aurantiochytrium sp. in response to lowtemperature stress. Furthermore, proteomics was used to interpret the molecular mechanisms underlying the increase of DHA contents of Aurantiochytrium sp. at low temperatures. The results showed that low temperatures inhibited cellular energy generation through glycolysis and the TCA cycle and led to a significant up-regulation of polyunsaturated fatty acid synthase (Ma et al., 2017).

\section{Theoretical Guidance for Rational Genetic Engineering}

Genetic engineering of microalgae guided by omics technologies has been increasingly applied. Based on an analysis of the transcriptome and lipidome of $C$. reinhardtii under heat stress, the key rate-limiting enzyme of DGAT was identified (Légeret et al., 2016). Overexpression of DGAT in C. reinhardtii resulted to a 9-fold increase in TAG content (Lamers et al., 2010). Similarity, DGAT was overexpressed in P. tricornutum, and the lipid content was enhanced from 27.5 to $37.2 \%$ (Remmers et al., 2017). Similar positive effects were also obtained in Nannochloropsis oceanica, S. obliquus, and Chlorella minutissima (Chen et al., 2016; Wei et al., 2017).

In addition to specific genes, omics technologies can identify global transcription factors that control lipid biosynthesis. For example, the PSR1 gene is related to stress due to phosphorus limitation. When PSR1 was overexpressed in C. reinhardtii, TAG accumulation was increased (Ngan et al., 2015). Recently, the transcription factor lipid remodeling regulator 1 (LRL1) was found in $C$. reinhardtii by transcriptomic analysis, which is a regulator of both membrane remodeling and TAG biosynthesis under phosphorus-limitation (Hidayati et al., 2019). In the future, LRL1 could be a potential target of engineering for improving lipid accumulation in microalgae.

Most stress-based induction strategies in microalgae generate ROS as by-products (Zhao et al., 2019). Antioxidant enzymes act as the first line of cellular defense against oxidative damage. In Schizochytrium sp., the expression levels of superoxide dismutase

\section{REFERENCES}

An, M., Mou, S., Zhang, X., Ye, N., Zheng, Z., Cao, S., et al. (2013). Temperature regulates fatty acid desaturases at a transcriptional level and modulates the fatty acid profile in the Antarctic microalga Chlamydomonas sp ICE-L. Bioresour. Technol. 134, 151-157. doi: 10.1016/j.biortech.2013.01.142

Bajhaiya, A. K., Dean, A. P., Driver, T., Trivedi, D. K., Rattray, N. J. W., Allwood, J. W., et al. (2016). High-throughput metabolic screening of microalgae genetic
(SOD) and catalase (CAT) under high salinity stress were upregulated by 4.82 and 3.11-fold, respectively. Similar effects were also observed in other microalgal species, which indicated that enhancing the activity of antioxidant enzymes may be beneficial for lipid production (Ugya et al., 2020). Accordingly, when SOD was overexpressed in Schizochytrium sp., the ROS levels were greatly reduced and the PUFA titer was increased by 32.9\% (Zhang et al., 2018).

\section{CONCLUSION}

Each species of microalgae has different optimal stress conditions for the overproduction of desired metabolites. In total, stressbased strategy is the most effective way to enhance lipid or carotenoid production in microalgae, although this might inhibit cell growth and induce oxidative damage. According to extensive analyses on technology and economy, a two-stage cultivation strategy gives rise to more operational and capital costs compared to a single cultivation system. Therefore, working out how to economically improve growth under stress conditions is a future development trend. Moreover, the key factors influencing cell growth and production of valuable molecules still need to be clarified. In recent years, massive "omics" datasets continue to be used to identify the key regulatory genes that are activated under stress conditions. However, our understanding of microalgal stress responses is currently limited to model species and prediction of gene function based on homology. The availability of genetic tools for microalgae is limited, and many are not well developed. Therefore, it is necessary to develop functional genomics research by applying multiple omics technologies and establish effective genetic manipulation tools for non-model microalgae species.

\section{AUTHOR CONTRIBUTIONS}

T-QS and L-RW conceived the idea and wrote the first draft of the manuscript. Z-XZ designed the figures and drafted the table. $\mathrm{X}$-MS contributed to manuscript revision and approved the final version. All authors read and approved the final manuscript.

\section{FUNDING}

This work was financially supported by the National Natural Science Foundation of China (No. 21908112) and the Nature Science Foundation of Jiangsu Province (Nos. BK20190706 and BK20170988).

variation in response to nutrient limitation. Metabolomics 12:9. doi: 10.1007/ s11306-015-0878-4

Beardall, J., Roberts, S., and Raven, J. A. (2005). Regulation of inorganic carbon acquisition by phosphorus limitation in the green alga Chlorella emersonii. Can. J. Bot. 83, 859-864. doi: 10.1139/b05-070

Bhosale, P. (2004). Environmental and cultural stimulants in the production of carotenoids from microorganisms. Appl. Microbiol. Biotechnol. 63, 351-361. doi: $10.1007 /$ s00253-003-1441-1 
Boussiba, S., and Vonshak, A. (1991). Astaxanthin accumulation in the green alga Haematococcus pluvialis. Plant. Cell. Physiol. 32, 1077-1082. doi: 10.1093/ oxfordjournals.pcp.a078171

Campo, J. A. D., Rodríguez, H., Moreno, J., Vargas, M. A., Rivas, J., and Guerrero, M. G. (2004). Accumulation of astaxanthin and lutein in Chlorella zofingiensis (Chlorophyta). Appl. Microbiol. Biotechnol. 64, 848-854. doi: 10.1007/s00253003-1510-5

Carfagna, S., Bottone, C., Cataletto, P. R., Petriccione, M., Pinto, G., Salbitani, G., et al. (2016). Impact of sulfur starvation in autotrophic and heterotrophic cultures of the extremophilic microalga Galdieria phlegrea (Cyanidiophyceae). Plant. Cell. Physiol. 57, 1890-1898. doi: 10.1093/pcp/pcw112

Carmen Ruiz-Dominguez, M., Vaquero, I., Obregon, V., de la Morena, B., Vilchez, C., and Vega, J. M. (2015). Lipid accumulation and antioxidant activity in the eukaryotic acidophilic microalga Coccomyxa sp (strain onubensis) under nutrient starvation. J. Appl. Phycol. 27, 1099-1108. doi: 10.1007/s10811-0140403-6

Chen, C.-Y., Kao, A.-L., Tsai, Z.-C., Chow, T.-J., Chang, H.-Y., Zhao, X.-Q., et al. (2016). Expression of type 2 diacylglycerol acyltransferse gene DGTT1 from Chlamydomonas reinhardtii enhances lipid production in Scenedesmus obliquus. Biotechnol. J. 11, 336-344. doi: 10.1002/biot.201500272

Chen, G., Wang, B., Han, D., Sommerfeld, M., Lu, Y., Chen, F., et al. (2015). Molecular mechanisms of the coordination between astaxanthin and fatty acid biosynthesis in Haematococcus pluvialis (Chlorophyceae). Plant. J. 81, 95-107. doi: $10.1111 /$ tpj.12713

Chisti, Y. (2007). Biodiesel from microalgae. Biotechnol. Adv. 25, 294-306. doi: 10.1016/j.biotechadv.2007.02.001

Chokshi, K., Pancha, I., Ghosh, A., and Mishra, S. (2017). Nitrogen starvationinduced cellular crosstalk of ROS-scavenging antioxidants and phytohormone enhanced the biofuel potential of green microalga Acutodesmus dimorphus. Biotechnol. Biofuels. 10:60. doi: 10.1186/s13068-017-0747-7

Chu, F.-F., Chu, P.-N., Shen, X.-F., Lam, P. K. S., and Zeng, R. J. (2014). Effect of phosphorus on biodiesel production from Scenedesmus obliquus under nitrogen-deficiency stress. Bioresour. Technol. 152, 241-246. doi: 10.1016/j. biortech.2013.11.013

Coesel, S. N., Baumgartner, A. C., Teles, L. M., Ramos, A. A., Henriques, N. M., Cancela, L., et al. (2008). Nutrient limitation is the main regulatory factor for carotenoid accumulation and for psyand pds steady state transcript levels in Dunaliella salina (Chlorophyta) exposed to high light and salt stress. Mar. Biotechnol. 10, 602-611. doi: 10.1007/s10126-008-9100-2

Converti, A., Casazza, A. A., Ortiz, E. Y., Perego, P., and Del Borghi, M. (2009). Effect of temperature and nitrogen concentration on the growth and lipid content of Nannochloropsis oculata and Chlorella vulgaris for biodiesel production. Chem. Eng. Process. 48, 1146-1151. doi: 10.1016/j.cep.2009.03.006

Del Campo, J. A., Moreno, J., Rodriguez, H., Vargas, M. A., Rivas, J., and Guerrero, M. G. (2000). Carotenoid content of chlorophycean microalgae: factors determining lutein accumulation in Muriellopsis sp (Chlorophyta). J. Biotechnol. 76, 51-59. doi: 10.1016/S0168-1656(99)00178-9

Ding, W., Cui, J., Zhao, Y. T., Han, B. Y., Li, T., Zhao, P., et al. (2019). Enhancing Haematococcus pluvialis biomass and $\gamma$-aminobutyric acid accumulation by two-step cultivation and salt supplementation. Bioresour. Technol. 2019:285. doi: 10.1016/j.biortech.2019.121334

Fu, L., Cui, X., Li, Y., Xu, L., Zhang, C., Xiong, R., et al. (2017). Excessive phosphorus enhances Chlorella regularis lipid production under nitrogen starvation stress during glucose heterotrophic cultivation. Chem. Eng. J. 330, 566-572. doi: 10.1016/j.cej.2017.07.182

Ge, F., Huang, W., Chen, Z., Zhang, C., Xiong, Q., Bowler, C., et al. (2014). Methylcrotonyl-CoA carboxylase regulates triacylglycerol accumulation in the model diatom Phaeodactylum tricornutum. Plant. Cell. 26, 1681-1697. doi: 10.1105/tpc.114.124982

Goodson, C., Roth, R., Wang, Z. T., and Goodenough, U. (2011). Structural correlates of cytoplasmic and chloroplast lipid body cynthesis in Chlamydomonas reinhardtii and stimulation of lipid body production with acetate boost. Eukaryot. Cell. 10, 1592-1606. doi: 10.1128/EC.05242-11

Guarnieri, M. T., and Pienkos, P. T. (2015). Algal omics: unlocking bioproduct diversity in algae cell factories. Photosynth. Res. 123, 255-263. doi: 10.1007/ s11120-014-9989-4

Guedes, A. C., Meireles, L. A., Amaro, H. M., and Malcata, F. X. (2010). Changes in lipid class and fatty acid composition of cultures of Pavlova lutheri, in response to light intensity. J. Am. Oil. Chem. Soc. 87, 791-801. doi: 10.1007/s11746-0101559-0

Gwak, Y., Hwang, Y.-S., Wang, B., Kim, M., Jeong, J., Lee, C.-G., et al. (2014). Comparative analyses of lipidomes and transcriptomes reveal a concerted action of multiple defensive systems against photooxidative stress in Haematococcus pluvialis. J. Exp. Bot. 65, 4317-4334. doi: 10.1093/jxb/eru 206

He, B., Hou, L., Dong, M., Shi, J., Huang, X., Ding, Y., et al. (2018). Transcriptome analysis in Haematococcus pluvialis: astaxanthin induction by high light with acetate and Fe2+. I. J. Mol. Sci. 19:175. doi: 10.3390/ijms19010175

He, Q. N., Yang, H. J., Wu, L., and Hu, C. X. (2015). Effect of light intensity on physiological changes, carbon allocation and neutral lipid accumulation in oleaginous microalgae. Bioresource. Technol. 191, 219-228. doi: 10.1016/j. biortech.2015.05.021

Hellier, P., Purton, S., and Ladommatos, N. (2015). Molecular structure of photosynthetic microbial biofuels for improved engine combustion and emissions characteristics. Front. Bioeng. Biotechnol. 3:49. doi: 10.3389/fbioe. 2015.00049

Hermawan, J., Masithah, E. D., Tjahjaningsih, W., and Abdillah, A. A. (2018). Increasing $\beta$-carotene content of phytoplankton Dunaliella salina using different salinity media. Iop. Conf. 137:012034. doi: 10.1088/1755-1315/137/1/ 012034

Hidayati, N. A., Yamada-Oshima, Y., Iwai, M., Yamano, T., Kajikawa, M., Sakurai, N., et al. (2019). Lipid remodeling regulator 1 (LRL1) is differently involved in the phosphorus-depletion response from PSR1 in Chlamydomonas reinhardtii. Plant. J. 100, 610-626. doi: 10.1111/tpj.14473

Ho, S.-H., Nakanishi, A., Kato, Y., Yamasaki, H., Chang, J.-S., Misawa, N., et al. (2017). Dynamic metabolic profiling together with transcription analysis reveals salinity-induced starch-to-lipid biosynthesis in alga Chlamydomonas $\mathrm{sp}$ JSC4. Sci. Rep. 7:45471. doi: 10.1038/srep45471

Ho, S.-H., Nakanishi, A., Ye, X., Chang, J.-S., Chen, C.-Y., Hasunuma, T., et al. (2015). Dynamic metabolic profiling of the marine microalga Chlamydomonas sp JSC4 and enhancing its oil production by optimizing light intensity. Biotechnol. Biofuels. 8:48. doi: 10.1186/s13068-015-0226-y

Hsieh, C.-H., and Wu, W.-T. (2009). Cultivation of microalgae for oil production with a cultivation strategy of urea limitation. Bioresour. Technol. 100, 39213926. doi: 10.1016/j.biortech.2009.03.019

Hu, Q., Sommerfeld, M., Jarvis, E., Ghirardi, M., Posewitz, M., Seibert, M. et al. (2008). Microalgal triacylglycerols as feedstocks for biofuel production: perspectives and advances. Plant. J. 54, 621-639. doi: 10.1111/j.1365-313x.2008. 03492.x

Hunter, J. E., Brandsma, J., Dymond, M. K., Koster, G., Moore, C. M., Postle, A. D., et al. (2018). Lipidomics of Thalassiosira pseudonana under phosphorus stress reveal underlying phospholipid substitution dynamics and novel diglycosylceramide substitutes. Appl. Environ. Microbiol. 84:e02034-17. doi: 10.1128/AEM.02034-17

Kanokwan, C., and Cornelis, V. (2012). Growth, fatty acid profile in major lipid classes and lipid fluidity ofaurantiochytrium mangroveisk-02 as a function of growth temperature. Braz. J. Microbiol. 43, 187-200. doi: 10.1590/S151783822012000100020

Kim, K., and Portis, A. R. (2004). Oxygen-dependent H2O2 production by Rubisco. FEBS. Lett. 571, 124-128. doi: 10.1016/j.febslet.2004.06.064

Krzeminska, I., Piasecka, A., Nosalewicz, A., Simionato, D., and Wawrzykowski, J. (2015). Alterations of the lipid content and fatty acid profile of Chlorella protothecoides under different light intensities. Bioresour. Technol. 196, 72-77. doi: 10.1016/j.biortech.2015.07.043

Kurpan Nogueira, D. P., Silva, A. F., Araujo, O. Q. F., and Chaloub, R. M. (2015). Impact of temperature and light intensity on triacylglycerol accumulation in marine microalgae. Biomass. Bioenergy. 72, 280-287. doi: 10.1016/j.biombioe. 2014.10.017

Lamers, P. P., Janssen, M., De Vos, R. C. H., Bino, R. J., and Wijffels, R. H. (2012) Carotenoid and fatty acid metabolism in nitrogen-starved Dunaliella salina, a unicellular green microalga. J. Biotechnol. 162, 21-27. doi: 10.1016/j.jbiotec. 2012.04.018

Lamers, P. P., van de Laak, C. C. W., Kaasenbrood, P. S., Lorier, J., Janssen, M. De Vos, R. C. H., et al. (2010). Carotenoid and fatty acid metabolism in lightstressed Dunaliella salina. Biotechnol. Bioeng. 106, 638-648. doi: 10.1002/bit. 22725 
Légeret, B., Schulz-Raffelt, M., Nguyen, H. M., Auroy, P., Beisson, F., Peltier, G., et al. (2016). Lipidomic and transcriptomic analyses of Chlamydomonas reinhardtii under heat stress unveil a direct route for the conversion of membrane lipids into storage lipids. Plant. Cell. Environ. 39, 834-847. doi: 10.1111/pce.12656

Lemoine, Y., and Schoefs, B. (2010). Secondary ketocarotenoid astaxanthin biosynthesis in algae: a multifunctional response to stress. Photosynth. Res. 106, 155-177. doi: 10.1007/s11120-010-9583-3

Li, X., Hu, H.-Y., Gan, K., and Sun, Y.-X. (2010). Effects of different nitrogen and phosphorus concentrations on the growth, nutrient uptake, and lipid accumulation of a freshwater microalga Scenedesmus sp. Bioresour. Technol. 101, 5494-5500. doi: 10.1016/j.biortech.2010.02.016

Li, Y., Han, D., Hu, G., Sommerfeld, M., and Hu, Q. (2010). Inhibition of starch synthesis results in overproduction of lipids in Chlamydomonas reinhardtii. Biotechnol. Bioeng. 107, 258-268. doi: 10.1002/bit.22807

Li, Y., Horsman, M., Wu, N., Lan, C.Q., and Dubois-Calero, N. (2008). Biofuels from microalgae. Biotechnol. Prog. 24, 815-820. doi: 10.1021/bp070371k

Li-Beisson, Y., Beisson, F., and Riekhof, W. (2015). Metabolism of acyl-lipids in Chlamydomonas reinhardtii. Plant. J. 82, 504-522. doi: 10.1111/tpj.12787

Liu, J., Mao, X., Zhou, W., and Guarnieri, M. T. (2016). Simultaneous production of triacylglycerol and high-value carotenoids by the astaxanthin-producing oleaginous green microalga Chlorella zofingiensis. Bioresour. Technol. 214, 319327. doi: 10.1016/j.biortech.2016.04.112

Liu, T., Li, Y., Liu, F., and Wang, C. (2016). The enhanced lipid accumulation in oleaginous microalga by the potential continuous nitrogen-limitation (CNL) strategy. Bioresour. Technol. 203, 150-159. doi: 10.1016/j.biortech.2015.12.021

Ma, T., Shi, B., Ye, Z., Li, X., Liu, M., Chen, Y., et al. (2018). Lipid engineering combined with systematic metabolic engineering of Saccharomyces cerevisiae for high-yield production of lycopene. Metab. Eng. 52, 134-142. doi: 10.1016/j. ymben.2018.11.009

Ma, Z., Tan, Y., Cui, G., Feng, Y., Cui, Q., and Song, X. (2015). Transcriptome and gene expression analysis of DHA producer Aurantiochytrium under low temperature conditions. Sci. Rep. 5:14446. doi: 10.1038/srep14446

Ma, Z., Tian, M., Tan, Y., Cui, G., Feng, Y., Cui, Q., et al. (2017). Response mechanism of the docosahexaenoic acid producer Aurantiochytrium under cold stress. Algal. Res. 25, 191-199. doi: 10.1016/j.algal.2017.05.021

Mulders, K. J. M., Janssen, J. H., Martens, D. E., Wijffels, R. H., and Lamers, P. P. (2014). Effect of biomass concentration on secondary carotenoids and triacylglycerol (TAG) accumulation in nitrogen-depleted Chlorella zofingiensis. Algal. Res. 6, 8-16. doi: 10.1016/j.algal.2014.08.006

Ngan, C. Y., Wong, C.-H., Choi, C., Yoshinaga, Y., Louie, K., Jia, J., et al. (2015). Lineage-specific chromatin signatures reveal a regulator of lipid metabolism in microalgae. Nat. Plants 1:15158. doi: 10.1038/nplants.2015.107

Pal, D., Khozin-Goldberg, I., Cohen, Z., and Boussiba, S. (2011). The effect of light, salinity, and nitrogen availability on lipid production by Nannochloropsis sp. Appl. Microbiol. Biotechnol. 90, 1429-1441. doi: 10.1007/s00253-011-3170-1

Phadwal, K., and Singh, P. K. (2003). Effect of nutrient depletion on b-carotene and glycerol accumulation in two strains of Dunaliella sp. Bioresour. Technol. 90, 55-58. doi: 10.1016/S0960-8524(03)00090-7

Pribyl, P., Cepak, V., and Zachleder, V. (2012). Production of lipids in 10 strains of Chlorella and Parachlorella, and enhanced lipid productivity in Chlorella vulgaris. Appl. Microbiol. Biotechnol. 94, 549-561. doi: 10.1007/s00253-0123915-5

Pugkaew, W., Meetam, M., Yokthongwattana, K., Leeratsuwan, N., and Pokethitiyook, P. (2019). Effects of salinity changes on growth, photosynthetic activity, biochemical composition, and lipid productivity of marine microalga Tetraselmis suecica. J. Appl. Phycol. 31, 969-979. doi: 10.1007/s10811-0181619-7

Rai, V., Muthuraj, M., Gandhi, M. N., Das, D., and Srivastava, S. (2017). Real-time iTRAQ-based proteome profiling revealed the central metabolism involved in nitrogen starvation induced lipid accumulation in microalgae. Sci. Rep. 7:45732. doi: 10.1038/srep45732

Ramos, A., Coesel, S., Marques, A., Rodrigues, M., Baumgartner, A., Noronha, J., et al. (2008). Isolation and characterization of a stress-inducible Dunaliella salina Lcy- $\beta$ gene encoding a functional lycopene $\beta$-cyclase. Appl. Microbiol. Biot. 79:819. doi: 10.1007/s00253-008-1492-4

Remmers, I. M., Martens, D. E., Wijffels, R. H., and Lamers, P. P. (2017). Dynamics of triacylglycerol and EPA production in Phaeodactylum tricornutum under nitrogen starvation at different light intensities. PLoS One 12:e175630. doi: 10.1371/journal.pone.0175630

Rosenberg, J. N., Oyler, G. A., Wilkinson, L., and Betenbaugh, M. J. (2008). A green light for engineered algae: redirecting metabolism to fuel a biotechnology revolution. Curr. Opin. Biotechnol. 19, 430-436. doi: 10.1016/j.copbio.2008.07.008

Ruenwai, R., Neiss, A., Laoteng, K., Vongsangnak, W., Dalfard, A. B., Cheevadhanarak, S., et al. (2011). Heterologous production of polyunsaturated fatty acids in Saccharomyces cerevisiae causes a global transcriptional response resulting in reduced proteasomal activity and increased oxidative stress. Biotechnol. J. 6, 343-356. doi: 10.1002/biot.201000316

Sakarika, M., and Kornaros, M. (2017). Kinetics of growth and lipids accumulation in, Chlorella vulgaris, during batch heterotrophic cultivation: effect of different nutrient limitation strategies. Bioresour. Technol. 243, 356-365. doi: 10.1016/j. biortech.2017.06.110

Sanchez, J. F., Fernandez, J. M., Acien, F. G., Rueda, A., Perez-Parra, J., and Molina, E. (2008). Influence of culture conditions on the productivity and lutein content of the new strain Scenedesmus almeriensis. Process. Biochem. 43, 398-405. doi: 10.1016/j.procbio.2008.01.004

Sayegh, F. A. Q., and Montagnes, D. J. S. (2011). Temperature shifts induce intraspecific variation in microalgal production and biochemical composition. Bioresour. Technol. 102, 3007-3013. doi: 10.1016/j.biortech.2010.10.011

Shen, X. F., Gao, L. J., Zhou, S. B., Huang, J. L., Wu, C. Z., Qin, Q. W., et al. (2020). High fatty acid productivity from Scenedesmus obliquus in heterotrophic cultivation with glucose and soybean processing wastewater via nitrogen and phosphorus regulation. Sci. Total. Environ. 708:7. doi: 10.1016/j.scitotenv.2019. 134596

Shi, Q., Gao, Z., Shi, T. Q., Song, P., Ren, L. J., and Huang, H. (2017). Reactive oxygen species-mediated cellular stress response and lipid accumulation in oleaginous microorganisms: the state of the art and future perspectives. Front. Microbiol. 8:793. doi: 10.3389/fmicb.2017.00793

Srinuanpan, S., Cheirsilp, B., Prasertsan, P., Kato, Y., and Asano, Y. (2018). Strategies to increase the potential use of oleaginous microalgae as biodiesel feedstocks: nutrient starvations and cost-effective harvesting process. Renew. Energy 122, 507-516. doi: 10.1016/j.renene.2018.01.121

Sun, L., Ren, L., Zhuang, X., Ji, X., Yan, J., and Huang, H. (2014). Differential effects of nutrient limitations on biochemical constituents and docosahexaenoic acid production of Schizochytrium sp. Bioresour. Technol. 159, 199-206. doi: 10.1016/j.biortech.2014.02.106

Takagi, M., Karseno, and Yoshida, T. (2006). Effect of salt concentration on intracellular accumulation of lipids and triacylglyceride in marine microalgae Dunaliella cells. J. Biosci. Bioeng. 101, 223-226. doi: 10.1263/jbb.101.223

Tripathi, U., Sarada, R., and Ravishankar, G. A. (2002). Effect of culture conditions on growth of green alga - Haematococcus pluvialis and astaxanthin production. Acta. Physiol. Plant 24, 323-329. doi: 10.1007/s11738-002-0058-9

Ugya, A. Y., Imam, T. S., Li, A., Ma, J., and Hua, X. (2020). Antioxidant response mechanism of freshwater microalgae species to reactive oxygen species production: a mini review. Chem. Ecol. 36, 174-193. doi: 10.1080/02757540. 2019.1688308

Urreta, I., Ikaran, Z., Janices, I., Ibanez, E., Castro-Puyana, M., Castanon, S., et al. (2014). Revalorization of Neochloris oleoabundans biomass as source of biodiesel by concurrent production of lipids and carotenoids. Algal. Res. 5, 16-22. doi: 10.1016/j.algal.2014.05.001

Van Wagenen, J., Miller, T. W., Hobbs, S., Hook, P., Crowe, B., and Huesemann, M. (2012). Effects of light and temperature on fatty acid production in Nannochloropsis Salina. Energies 5, 731-740. doi: 10.3390/en503 0731

Wan, M., Zhang, J., Hou, D., Fan, J., Li, Y., Huang, J., et al. (2014). The effect of temperature on cell growth and astaxanthin accumulation of Haematococcus pluvialis during a light-dark cyclic cultivation. Bioresour. Technol. 167, 276-283. doi: 10.1016/j.biortech.2014.06.030

Wang, F., Gao, B., Wu, M., Huang, L., and Zhang, C. (2019). A novel strategy for the hyper-production of astaxanthin from the newly isolated microalga Haematococcus pluvialis JNU35. Algal. Res. 39:101466. doi: 10.1016/j.algal. 2019.101466

Wang, T., Ge, H., Liu, T., Tian, X., Wang, Z., Guo, M., et al. (2016). Salt stress induced lipid accumulation in heterotrophic culture cells of Chlorella protothecoides: mechanisms based on the multi-level analysis of oxidative 
response, key enzyme activity and biochemical alteration. J. Biotechnol. 228, 18-27. doi: 10.1016/j.jbiotec.2016.04.025

Ward, O. P., and Singh, A. (2005). Omega-3/6 fatty acids: alternative sources of production. Process. Biochem. 40, 3627-3652. doi: 10.1016/j.procbio.2005. 02.020

Wei, H., Shi, Y., Ma, X., Pan, Y., Hu, H., Li, Y., et al. (2017). A type-I diacylglycerol acyltransferase modulates triacylglycerol biosynthesis and fatty acid composition in the oleaginous microalga. Nannochloropsis oceanica. Biotechnol. Biofuels. 10:174. doi: 10.1186/s13068-017-0858-1

Xie, Y., Ho, S.-H., Chen, C.-N. N., Chen, C.-Y., Ng, I. S., Jing, K.-J., et al. (2013). Phototrophic cultivation of a thermo-tolerant Desmodesmus sp for lutein production: effects of nitrate concentration, light intensity and fedbatch operation. Bioresour. Technol. 144, 435-444. doi: 10.1016/j.biortech.2013. 06.064

Yang, L., Chen, J., Qin, S., Zeng, M., Jiang, Y., Hu, L., et al. (2018). Growth and lipid accumulation by different nutrients in the microalga Chlamydomonas reinhardtii. Biotechnol. Biofuels. 11:40. doi: 10.1186/s13068-018-1041-z

Yang, Y., Mininberg, B., Tarbet, A., and Weathers, P. (2013). At high temperature lipid production in Ettlia oleoabundansoccurs before nitrate depletion. Appl. Microbiol. Biotechnol. 97, 2263-2273. doi: 10.1007/s00253-012-4671-2

Yao, C., Jiang, J., Cao, X., Liu, Y., Xue, S., and Zhang, Y. (2018). Phosphorus enhances photosynthetic storage starch production in a green microalga (Chlorophyta) Tetraselmis subcordiformis in nitrogen starvation conditions. J. Agr. Food. Chem. 66, 10777-10787. doi: 10.1021/acs.jafc.8b04798
Zhang, S., He, Y., Sen, B., Chen, X., Xie, Y., Keasling, J. D., et al. (2018). Alleviation of reactive oxygen species enhances PUFA accumulation in Schizochytrium sp. through regulating genes involved in lipid metabolism. Metab. Eng. Commun. 6, 39-48. doi: 10.1016/j.meteno.2018.03.002

Zhao, Y., Wang, H.-P., Han, B., and Yu, X. (2019). Coupling of abiotic stresses and phytohormones for the production of lipids and high-value by-products by microalgae: a review. Bioresour. Technol. 274, 549-556. doi: 10.1016/j.biortech. 2018.12.030

Zhao, Y., Yue, C., Ding, W., Li, T., Xu, J.-W., Zhao, P., et al. (2018). Butylated hydroxytoluene induces astaxanthin and lipid production in Haematococcus pluvialis under high-light and nitrogen-deficiency conditions. . Technol. 266, 315-321. doi: 10.1016/j.biortech.2018.06.111

Conflict of Interest: The authors declare that the research was conducted in the absence of any commercial or financial relationships that could be construed as a potential conflict of interest.

Copyright $(2020$ Shi, Wang, Zhang, Sun and Huang. This is an open-access article distributed under the terms of the Creative Commons Attribution License (CC BY). The use, distribution or reproduction in other forums is permitted, provided the original author(s) and the copyright owner(s) are credited and that the original publication in this journal is cited, in accordance with accepted academic practice. No use, distribution or reproduction is permitted which does not comply with these terms. 